\title{
TURNING 3D DATA SURVEYS OF INTERTIDAL ZONES INTO NEW MODES OF 3D VISUALIZATION, SIMULATION AND SPATIAL INTERFACE EXPERIENCES
}

\author{
N. Hedley ${ }^{1,}$ I. Lochhead ${ }^{1 *}$ \\ ${ }^{1}$ Department of Geography, Simon Fraser University, Burnaby, Canada - (hedley, iml) @ sfu.ca
}

Commission IV, WG IV/9

KEY WORDS: 3D data, spatial interface research, visualization, simulation, intertidal

\begin{abstract}
:
This paper reports on Intertidal - a collaborative project to demonstrate integrated workflows to 3D spatial data infrastructure (SDI), simulations and geovisual interfaces - as integrated approaches to support the 3D characterization of coastal morphology, intertidal dynamics, potential sea level rise, and mitigation responses to them. Specifically, this project emphasized the potential of emerging 3D data, new analytical visualization methods, and emerging 3D interface technologies as ingredients of emerging and future environmental data science and visualization practice of coastal/intertidal environments.
\end{abstract}

\section{INTRODUCTION}

Environmental change driven by climate change has the potential to manifest in multiple ways. Sea level rise (SLR) is often one of the most commonly discussed potential outcomes of climate change. Intergovernmental Panel on Climate Change (IPCC) projections are often expressed in terms of degrees of average warming. Similarly, projected SLR is often expressed in terms of probabilities of (positive) change in average sea level.

It is easy to get lost, overwhelmed, or perhaps confused by the multitude of factors and scales of variables and potential outcomes in this problem space. What does $10 \mathrm{~cm}$ of sea level rise mean in New York City, versus Bangladesh, or Malé? What is the relationship between the data we collect, and our ability to perceive the implications of these projections?

Over the past decade, a constellation of researchers have collectively begun exploring the potential to transform public perception and awareness of climate change impacts, using a range of conventional, and, more recently, novel visualization platforms (Al-Kodmany 2002; Sheppard, 2005; Lai, Chang, Chan, Kang and Tan, 2011; Schroth et al., 2015; Fenech, Chen, Clark and Hedley 2017; Reyes and Chen, 2017; De Santis et al., 2018; De Santis et al., 2019; Macchione et al., 2019; Jacquinod and Bonaccorsi, 2019).

At the same time, there is a perpetual need to support local governments and the challenges they face to mitigate and manage risks in a changing environmental context (Henstra et al., 2019a; 2019b).

At local scales, municipal governments in coastal environments have a considerable responsibility and challenge, to mitigate risks. Policy, education and management practices can all play a role in productive mitigation of these risks. However, central to mitigating risk, is the ability to characterize it. Over the past two decades, spatial data surveys have been transformed by the advances and maturation of laser scanning technology, platforms and methods. Similarly, in photogrammetry, structure-frommotion (SfM) has been widely adopted as an agile, low-cost surveying workflow in science, industry and government. (Westoby et al., 2012). Each have significantly influenced the granularity of geomorphometry, and the sophistication of analyses that can be performed.

The emergence of dedicated climate futures visualization research was, in part, the result of a need to analytically visualize spatial environments in ways that conventional spatial mapping software did not - in order to tease out representational nuances and perceptual opportunities that might allow scientists, managers and policy-makers see physical spaces and subtle phenomena, in new ways.

While geographical information systems have evolved considerably over the past decades, their primary purpose, as working spatial analytical tools, means that they are often too abstract for comfortable use by policymakers in engagements with society and citizens.

This is perhaps why the more recent groundswell of $3 \mathrm{D}$ environmental visualization work has adopted and integrated novel 3D visualization platforms, such as 3D game engines, as the foundation for spatially rigorous, but visually compelling, and engaging climate change visualization systems.

Less overwhelming abstract information, enhanced geographical realism (resulting from rendering engines derived in AAA game technology), sophisticated 3D topological representation, 3D physics engines, artificial intelligence algorithms, and streamlined interactivity - have attracted geographic visualization experts as an incredibly rich environment with which to create distinctive and spatially rigorous visualizations $f$ environmental change.

This watershed has not gone unnoticed by the commercial GIS community, and has resulted in increasing interplay between the spatial analytical industry (such as Bentley, ESRI, QGIS, the game-building community (such as Unity, Unreal), and a wide range of developers and users. Most noticeably, have been the appearance of plugins and extensions in many spatial analytical platforms, to allow them to interoperate with prominent game engines directly, and via engagement with the 3D digital asset and production ecosystems.

It is also significant, that the inherently three-dimensional data products that these methods produce, or that which can be 
derived from them, are also contributing to a groundswell of effort to produce completely 3D geographical information systems, analyses, visualizations and visualization interfaces.

\section{APPLIED WORK}

This paper summarizes an experimental project, to use prototype workflows, experimental analytical simulations, and geovisual interface technologies in coastal data collection and analytical visualization. It was undertaken to enable the engineering department of a municipal government in coastal British Columbia, Canada, to observe the individual and combined potential of: new intertidal survey/data acquisition methods; new geomorphometric processing workflows and data products; $3 \mathrm{D}$ analytical simulations of intertidal zones to validate the impact of municipal management practices (beach armoring); and implementation of 3D visualization environments using emerging interface platforms.

\section{WORKFLOW, METHODS AND OUTPUTS}

We pursued a multi-phase project, to develop and explore these workflows. First, we conducted a multi-faceted 3D coastal/intertidal capture and characterization campaign, using laser scanning, and photogrammetry (Figure 1).

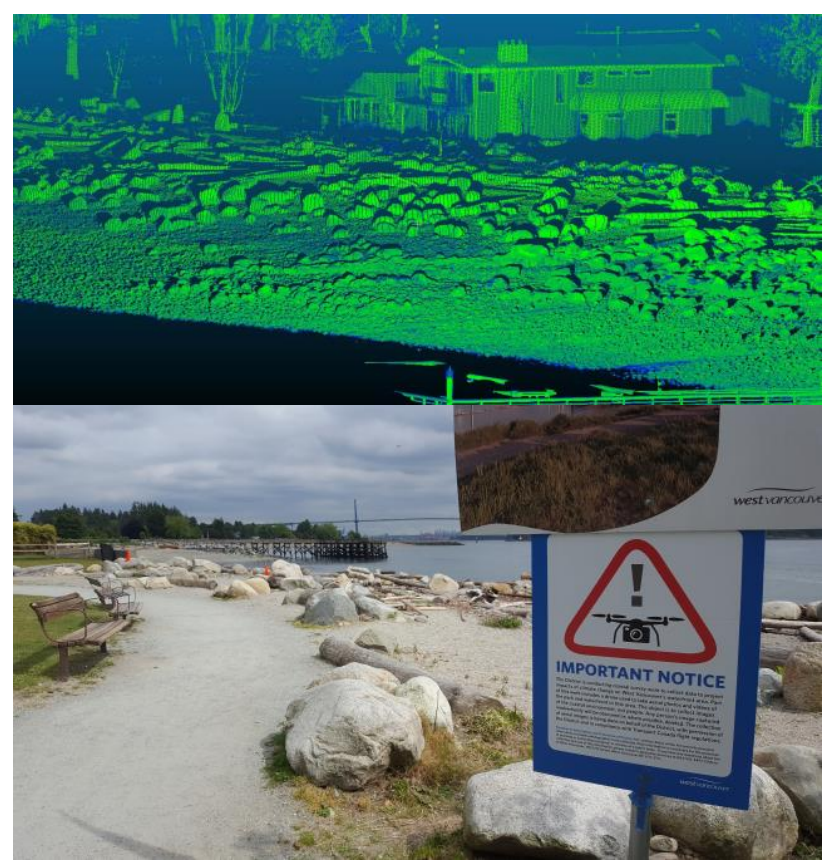

Figure 1. Images from our data survey campaign. Top: view of raw point cloud captured during terrestrial laser scanning of intertidal beach environment. Bottom: in partnership with local municipality and with authorization from federal aviation authorities, we conducted airborne imaging, which we processed using Structure-from-Motion methods.

Images from airborne surveys described were processed using Agisoft PhotoScan Professional (V1.4.0). Dense point clouds were created using the high-quality setting and depth filtering was set to aggressive. Point clouds were then cleaned to remove erroneous points and high-polygon count meshes were created as necessary. The ground resolution of our images was as fine as 0.012 meters, and the derived digital elevation models (DEM) has resolutions of as fine as 0.032 meters.

We then integrated our new 3D data assets, with municipal data, and developed a comparative data visualization product, in which the user could interactively toggle between past and current topographic data assets, in order to inspect and compare the representational veracity produced by each (Figure 2 ).

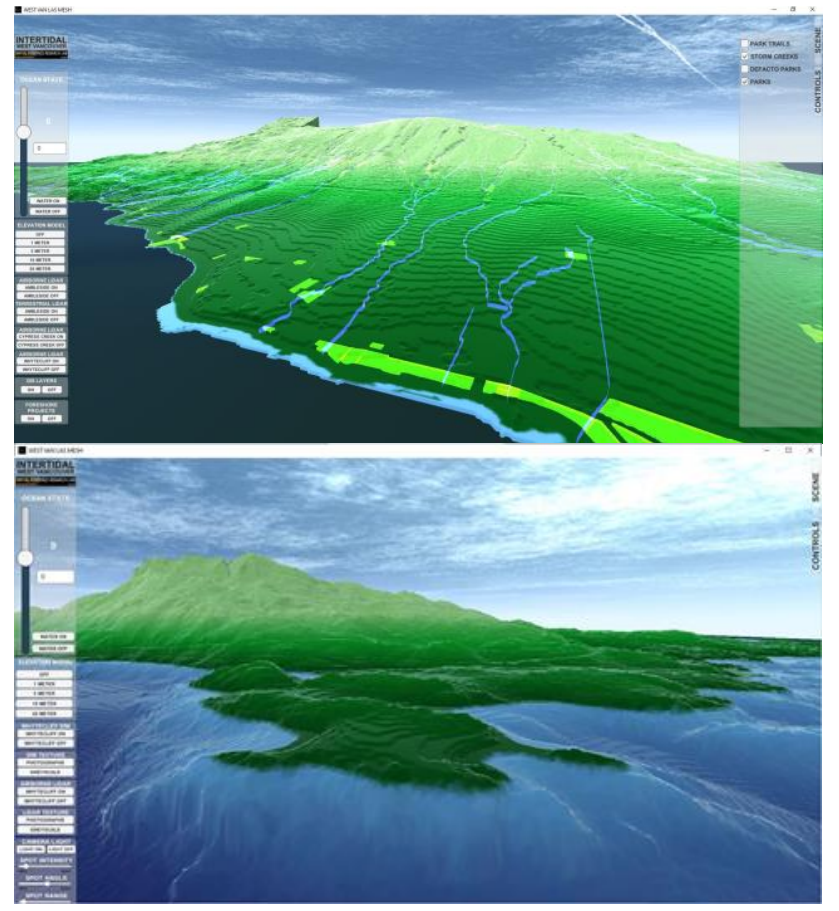

Figure 2: view of our comparative data fusion tool supporting comparison and inspection of all available topographic data sets in order to evaluate representational veracity and resolvable features.

\section{DEVELOPING 3D VISUALIZATIONS AND INTERFACES OF INTERTIDAL SPACES}

In addition to producing new high resolution datasets (as fine as $1 \mathrm{~cm}$ resolution), this project produced a set of 3D interface prototypes, each of which helped us explore the potential of datadriven 3D spatial interfaces, as new mediums through which to transform the way we connect with intertidal phenomena through data, and fundamentally new ways to conduct spatial information science.

These prototypes included: 3D fluid simulations in and across intertidal spaces, revealing exactly how beach armoring practices modify ocean velocity (Figure 3 ); immersive virtual reality (VR) environments allowing users walk around a $\sim 1 \mathrm{~cm}$-resolution virtual reconstruction of a marine park and interactively manipulate the ocean, to understand future sea levels and their intersection with high fidelity intertidal spaces (Figure 4); and a tabletop augmented reality (AR) sea level visualization tool intertidal zone at different future sea levels (Figure 5). We also developed visualization tools (not shown here) that allowed users to look through a window of a physical lab or class space, and into our 3D data display space; and finally, a 3D virtual world, in which the dynamic 3D sea level and sea state was driven by live buoy data, in real time. 


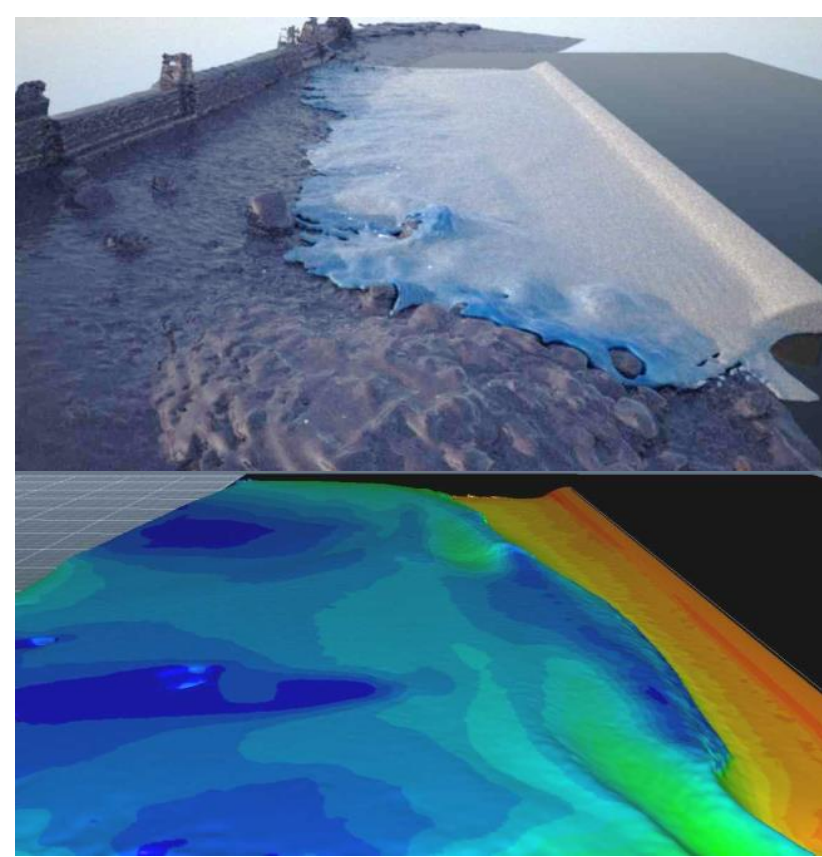

Figure 3. 3D simulations of effect of beach morphology on tidal dynamics. The upper images show a 3D smoothed particle hydrodynamics simulation running on our $1 \mathrm{~cm}$ resolution intertidal dataset. The lower image shows one of our simulations modified to show velocity gradients as the water interacts with variable beach morphology.
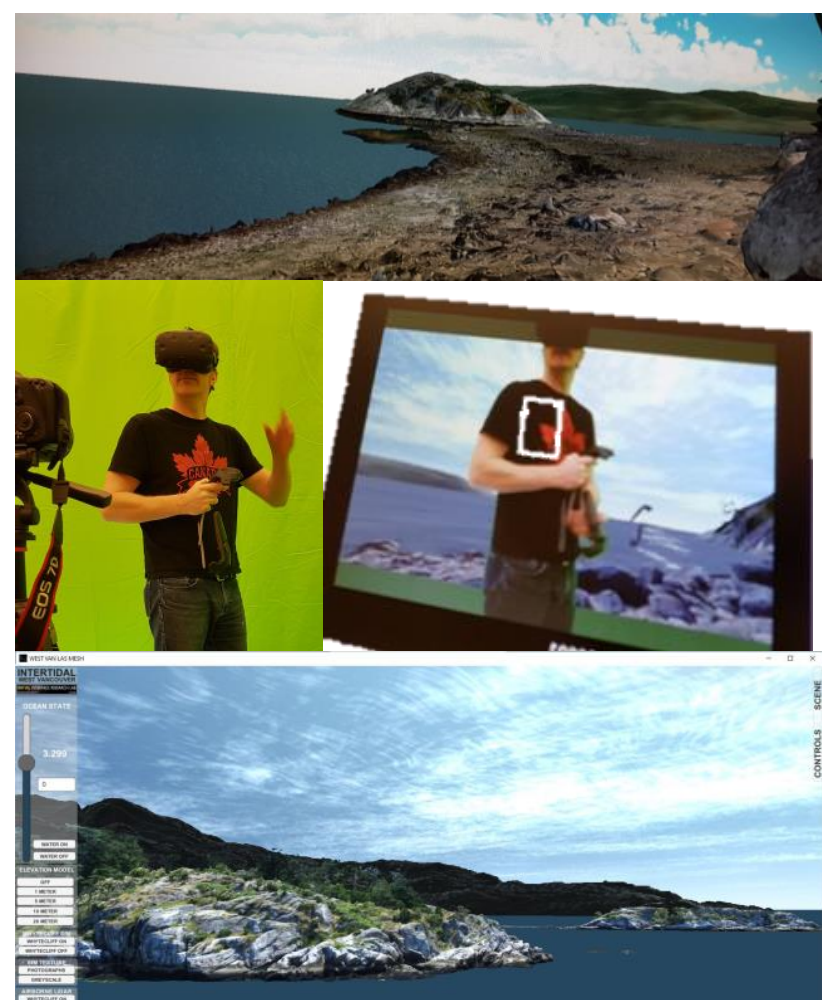

Figure 4. Views from inside and outside of Intertidal $V R$ - and immersive virtual reality system allowing municipal planners and citizens to walk around a $1 \mathrm{~cm}$-resolution virtual intertidal space, and interactive control total sea-level (with segmented mean sea-level, storm state), and not just observe, but experience its potential impact on a familiar community coastal space.

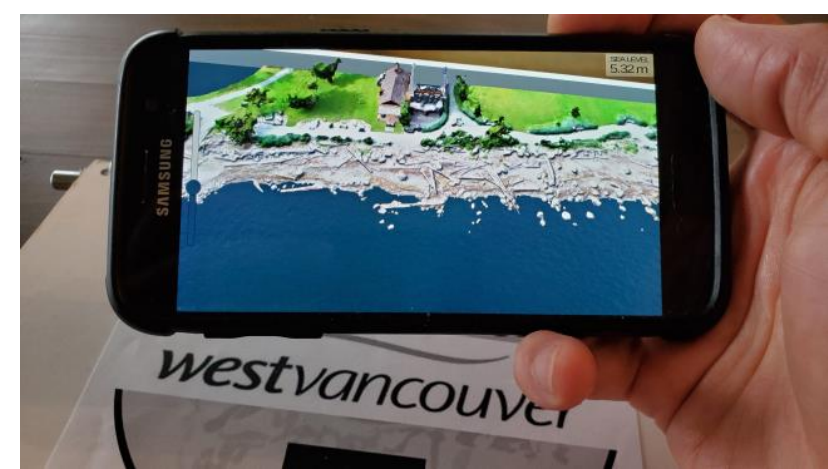

Figure 5. Our interactive tabletop AR prototype - allowing on-the-fly control of a moveable sea surface intersecting with $1 \mathrm{~cm}$ resolution intertidal zone.

\section{SUMMARY}

Together, these prototypes demonstrate emerging (perhaps provocative) modes of potential 3D data use in municipal planning and community knowledge mobilization (aligning with the work of Haynes et al. 2019; 2016). Fundamentally, they reveal (and perhaps challenge us to think of) new ways of thinking about how we connect with environmental spaces using data, enabled by 3D interface workflows. Moving beyond simply adopting emerging interface devices, they demonstrate a multitude of ways we can deliver transformative user experiences with phenomenon-centric data visualizations, tuned to a variety of conventional workspaces. In doing so, we also demonstrate an opportunity to redefine our relationships with environmental phenomena, by defining the ways we can interface with them.

The significance of this prospect was evident in the reaction of our municipal partners, when we brought the work full-circle, and placed these new tools in their hands. They had new tools to perform environmental interpretation and management, visualize real-time ocean conditions, quickly process simulations of beach management strategies, sea level rise futures - using immersive VR, or tabletop AR with which they could teleport 3D data visualizations into collaborative workspaces.

\section{ACKNOWLEDGEMENTS}

This work was supported by the Marine Environmental Observation Planning and Research Network of Centres of Excellence of Canada (MEOPAR NCE), grant number - in partnership with the Engineering Department of the District of West Vancouver, BC.

\section{REFERENCES}

Al-Kodmany, K. (2002). Visualization tools and methods in community planning: from freehand sketches to virtual reality. Journal of Planning Literature, 17(2), 189-211.

De Santis, R., Macchione, F., Costabile, P., \& Costanzo, C. (2018). A comparative analysis of 3-D representations of urban flood map in virtual environments for hazard communication purposes. In E3S Web of Conferences (Vol. 40, p. 6037). EDP Sciences.

De Santis, R., Macchione, F., Costabile, P., \& Costanzo, C. (2019). Visual Risk Communication of Urban Flooding in 3D Environments Based on Terrestrial Laser Scanning. In G. Mannina (Ed.), New Trends in Urban Drainage 
Modelling. UDM 2018. Green Energy and Technology (pp. 783-787). Cham: Springer International Publishing.

Fenech, A., Chen, A., Clark, A., \& Hedley, N. (2017). Building an adaptation tool for visualizing the coastal impacts of climate change on Prince Edward Island, Canada. In Climate change adaptation in North America (pp. 225238). Springer.

Haynes, P., Hehl-Lange, S., \& Lange, E. (2018). Mobile Augmented Reality for Flood Visualisation. Environmental Modelling \& Software, 109, 380-389.

Haynes, P., \& Lange, E. (2016). In-situ flood visualisation using mobile AR. In 2016 IEEE Symposium on 3D User Interfaces (3DUI) (pp. 243-244). IEEE.

Henstra, D., Minano, A., \& Thistlethwaite, J. (2019). Communicating disaster risk? An evaluation of the availability and quality of flood maps. Natural Hazards and Earth System Sciences, 19(1), 313-323.

Henstra, D., Thistlethwaite, J., Brown, C., \& Scott, D. (2019). Flood risk management and shared responsibility: Exploring Canadian public attitudes and expectations. Journal of Flood Risk Management, 12(1), e12346.

Jacquinod, F., \& Bonaccorsi, J. (2019). Studying Social Uses of 3D Geovisualizations: Lessons Learned from ActionResearch Projects in the Field of Flood Mitigation Planning. ISPRS International Journal of GeoInformation, $8(2), 84$.

Lai, J.-S., Chang, W.-Y., Chan, Y.-C., Kang, S.-C., \& Tan, Y.-C. (2011). Development of a 3D virtual environment for improving public participation: Case study-The Yuansantze Flood Diversion Works Project. Advanced Engineering Informatics, 25(2), 208-223.

Macchione, F., Costabile, P., Costanzo, C., \& De Santis, R. (2019). Moving to 3-D flood hazard maps for enhancing risk communication. Environmental Modelling \& Software, 111, 510-522.

Reyes, M. E. P., \& Chen, S.-C. (2017). A 3D virtual environment for storm surge flooding animation. In 2017 IEEE third international conference on multimedia big data (BigMM) (pp. 244-245). IEEE.

Schroth, O., Pond, E., \& Sheppard, S. (2015). Evaluating presentation formats of local climate change in community planning with regard to process and outcomes. Landscape and Urban Planning, 142, 147-158.

Sheppard, S. (2005). Landscape visualisation and climate change: the potential for influencing perceptions and behaviour. Environmental Science \& Policy, 8(6), $637-$ 654.

Westoby, M. J.; Brasington, J.; Glasser, N. F.; Hambrey, M. J.; Reynolds, J. M. (2012-12-15). 'Structure-from-Motion' photogrammetry: A low-cost, effective tool for geoscience applications". Geomorphology. 179: 300-314. 